\title{
Supporting Student Learning in Foundation Programmes and Beyond: Using Legitimation Code Theory as a Theoretical Lens to Think about Transition
}

\author{
Honjiswa Conana \\ Delia Marshall \\ Deon Solomons
}

\begin{abstract}
In South Africa, foundational provision and extended curriculum programmes (ECPs) have become one means of widening epistemological access to higher education and addressing high attrition rates among undergraduate students. Despite the evidence that epistemological access to the science disciplines is an ongoing process which extends beyond the first year, there is a paucity of research on the 'epistemic transitions' throughout the undergraduate curriculum, and in particular, the transition to second year. In this paper, tools from the Semantics dimension of Legitimation Code Theory (LCT) are used to analyse the pedagogical practices in ECP and second year physics and mathematics courses, as a means to develop insights into the challenges students face in making the transition to second year. Data is drawn from video-recordings and classroom observation notes, as well as from interviews with second year students. The LCT analysis highlights mismatches between the ECP and second year pedagogical practices, including increased pacing, a curtailed semantic range concentrated at an abstract level, less semantic waving, a narrower range of representations used (and less explicit unpacking of these), and less interactive engagement. Implications for second year pedagogical practices are discussed, in relation to normative and transformative approaches to foundational provision.
\end{abstract}

Keywords: foundation provision, extended curriculum programme, Legitimation Code Theory, transition, second year, Physics, epistemological access 


\section{Introduction}

In South Africa, studies on student access, throughput and retention in higher education show that these remain skewed along racial lines (CHE 2013: Scott, Yeld \& Hendry 2007). Within STEM (science, technology, engineering and mathematics) fields, in particular, these studies show high attrition at first year level, as well as low overall completion rate and a very small number of students who complete their degrees within the regulation time. Within the physical science field, specifically, only $21 \%$ of students at contact universities complete their degrees in the minimum time (three years). A recent review of undergraduate physics education undertaken by the Council on Higher Education and South African Institute of Physics (CHE-SAIP 2013) highlighted concerns about the under-preparedness of students entering first year physics and the level of graduate competence when completing their first degree.

In this context, foundational provision and extended curriculum programmes (ECPs) have become one means of addressing these equity and access concerns. Foundational provision in South Africa has a complex and contested history, arising a full decade before democratic change in South Africa (for an overview of the origins and educational philosophies underpinning science foundational provision, see Kloot et al. 2009; Rollnick 2010). In science ECPs, the educational orientations have included a focus on developing key conceptual foundations in disciplines (see, for example, Potgieter \& Davidovitz 2011; Engelbrecht et al. 2010), developing academic literacy skills (Jacobs 2007) and developing approaches to enhance meaningful science learning (Starfield \& Hart 1992; Short \& Jurgens 2011; Grayson 2010). In the context of widening access, the concept of 'epistemological access' (Morrow 1993) has been a common framing of many foundational and ECP programmes. Here, attention is drawn to helping students to access the 'discourse' of a discipline (Gee 2005), comprising the disciplinary knowledge and norms. Taking on a disciplinary discourse entails not only a cognitive process, but includes notions of identity and affect (see, for example, CollierReed et al. 2010). Gee's notion of discourse/Discourse is useful for making clear that gaining access to a discipline entails both the knowledge practices (what could be seen as the 'little d' discourse), as well as the broader values, attitude and dispositions associated with the discipline (the 'big' D' Discourse) (Gee 2005). Research by Ellery (2017) on ECP students' experiences of a foundation course explores how students are inducted into the ways of thinking of science disciplines. Using the Specialisation code of Legitimation Code 
Theory, she has explored the dispositions, values the ways of thinking (termed here, the 'gaze') ideally needed for success in undergraduate science studies.

Underlying the 'widening access' agenda of foundational provision is an intention to induct students into disciplinary knowledge on the one hand, and to develop a more critical stance in relation to that knowledge on the other hand. This dual-focus is taken up in the literature in several different, but complementary, forms. The academic literacies literature distinguishes between normative and transformative approaches (Lillis \& Scott 2007): a normative approach emphasizes inducting students into the norms of a discipline, whereas in a transformative approach, the emphasis is on opening up the disciplinary norms and ways of knowing to critique and contestation. Similarly, Moje (2007) makes the useful distinction between socially just pedagogy and pedagogy for social justice. From this perspective, the intention of foundational provision in widening epistemological access to science studies can be viewed as socially just pedagogy, since the focus is on inducting students - traditionally marginalized from science studies - into the 'powerful knowledge' (Young \& Muller 2013) of the sciences.

On the other hand, a pedagogy for social justice would entail taking a critical stance towards this so-called powerful knowledge. This might take the form of discussion on the wider social, historical and ethical dimensions of science, asking questions such as in whose interests this knowledge is used? Or discussing the limits of this knowledge in addressing issues such as climate change, sustainability and increasing inequality (Hugo 2016; Carstens 2016). It might also take a more critical angle on how scientific knowledge is often portrayed in traditional teaching; in other words, critiquing what has been termed the 'received view' of science (Cobern 1998:8) - as value-neutral, ahistorical and decontextualized from social contexts.

In the context of foundational provision in science, it could be argued that a normative approach, focusing on induction into disciplinary norms should precede a transformative approach, and that critique of those disciplinary norms may in fact destabilize students. However, as we have argued elsewhere (Conana, Marshall \& Case 2016), transformative approaches to STEM teaching that include taking a critical stance towards science knowledge may in fact make science more accessible and less alienating to students. These approaches could include foregrounding the historical and human side of doing science, and challenging the perception of science as a body of knowledge developed in some other geographical location and 
historical time period (Lemke 1990). These approaches could also explore science as a way of knowing in relation to other knowledge forms, to counter the 'scientism' perspectives often implicit in undergraduate science degrees (i.e. the view that science is the most authoritative viewpoint in relation to other forms of knowledge). These transformative approaches to foundational provision are particularly important in the current South African higher education context of debates on curriculum reform and 'decolonisation', which foreground perceptions that contemporary scientific knowledge may be experienced as alienating and lacking in relevance by students. Although elsewhere we have written about transformative approaches to foundational provision (Conana, Marshall \& Case 2016), in this paper the focus is primarily on the induction of students into disciplinary knowledge.

\section{The Transition to Second Year}

In considering epistemological access to the sciences, induction into disciplinary knowledge is an ongoing process, which begins in the first year and extends beyond that. However, in the South African literature on foundational provision, there is not much research on the transition to second year. This is in fact an international trend, with most studies focused on students' experiences of the first year, or on their exit-level outcomes. This is despite the fact that the transition from first year to second year is noted as a challenge for many students in undergraduate programmes around the world (see, for example, Hunter et al. 2010; Yorke 2015).

One common challenge identified is that at the second year level, students often begin to engage with material with which they have had very little prior experience (Milsom \& Yorke 2015). Another challenge identified in the literature on the transition to second year arises from the 'spiral curriculum' (Bruner 1960) structure of many higher education curricula. As Milsom \& Yorke (2015: 17) note, since curricula mostly consist of several disciplines, there are "potentially multiple spirals in operation at the same time'. For example, in a physics curriculum, certain mathematics concepts would be crucial prior knowledge required for physics courses, and so curriculum cohesion requires 'bridging between spiral strands' (Milsom \& Yorke 2015:17).

In South Africa, the challenging transition from first year to second year is especially the case for students moving from a foundation or extended 
degree programme into the so-called mainstream second year. Lubben (2007) in study of an undergraduate extended physics programme noted that students struggled with the discontinuity in teaching approaches between first and second year physics courses. Smith, Case \& Walbeek (2014:636), question 'the efficacy of a model that focuses largely on first year academic interventions'. They show that these models influenced students' performance in the first year but did not improve the overall graduation rate of students. Rollnick (2010) has suggested that changes to the curricula and pedagogies beyond the first year are what are needed. This is also argued in a recent CHE (2013) report which highlights the importance of 'epistemic transitions' throughout the undergraduate curriculum, and notes that curriculum reform needs to address these key transitions. The report argues that foundational provision needed to extend beyond the first year of a programme.

In this paper, we examine the transition that science students experience from an ECP physics course into their mainstream second year courses. Legitimation Code Theory (LCT) is introduced as a useful theoretical lens to think about this transition. We use LCT to characterize the sort of pedagogy prevalent in ECP programmes and then use LCT to identify some of the difficulties students experience in the transition to second year.

\section{Context of the Study}

The study is located in an extended curriculum programme in a Faculty of Natural Sciences. In the Physics Department, the programme centres on foundation provision in first year physics and mathematics courses, which are full credit courses spread over two years. This model can best be described as a 'slow-intensive' programme (Boughey 2010) with additional innovative course components, whose purpose is to address the 'articulation gap' (CHE 2013:17) between secondary and higher education in South Africa.

The ECP physics course covers the same topics as the mainstream first year course, but the extra time allows more curriculum space for foundational provision, which includes strengthening conceptual understanding, a focus on the nature of physics knowledge, and on the processes of scientific enquiry and modeling (van Heuvelen 1991; Etkina \& van Heuvelen 2007). It also allows time for the development of students' social capital, through site visits, exposure to research taking place in the department, and class-visits by former students now in industry or research. The course is taught in a flat-space venue, 
conducive to groupwork and enabling interactive engagement between lecturers and students. In this way a classroom learning community is created, in which discussion about science is fostered.

Drawing on the work of Gee (2005) and other studies in a sociolinguistics vein (Lemke 1990; Airey \& Linder 2009), the course is framed by an explicit focus on helping students to access the disciplinary discourse of physics (for further details, see Marshall \& Case 2010). This disciplinary discourse would include the values, attitudes, habits of mind that are particular to physicists ('the big D' Discourse) as well as the way the discipline represents itself semiotically (the 'little d' discourse). Here, the focus is on developing students' mastery of the multiple representations used in physics, including oral and written language, gestures, graphs, diagrams, mathematics etc. (for further details on developing representational competence, see Conana, Marshall and Case (in press). Drawing on physics education research, the teaching focuses explicitly on these multiple representations, in developing a 'representation-rich learning environment' (Rosengrant et al. 2009:010108-2), which helps students to learn how to use representations, and to appreciate the disciplinary affordances of representations (Kress 2010; Doran 2016). The course also presents the discipline of physics in its wider context social, historical and ethical contexts.

However, despite the extensive foundational provision of the ECP, seeming to give students a solid foundation in physics and mathematics, students' transition to second year remains an ongoing challenge. Second year Physics becomes more mathematically demanding, and students face the wellnoted challenge of applying the mathematics learned in their Mathematics courses to their Physics courses (Bing \& Redish 2009). As a Teaching and Learning specialist, one of the authors began to work alongside the second year physics and mathematics lecturers in order to better understand students' transition challenges. Tools from Legitimation Code Theory proved useful in characterizing the pedagogical practices in these courses, and in beginning to tease out the obstacles students experienced in making this transition.

\section{LCT as a Tool for Thinking about Access to Science}

As noted earlier, the ECP was framed in its design by insights from sociolinguistics-inspired studies on disciplinary discourse and science learning (Gee 2005; Lemke 1990; Airey \& Linder 2009). In analyzing the disciplinary 
discourse features of episodes in the physics classroom, we found that tools from the Semantics dimension of Legitimation Code Theory were useful for fine-grained analysis of physics teaching and tasks.

LCT is a sociological 'toolkit' (Maton 2014b:15) developed by Karl Maton, which incorporates and extends key concepts from the work of sociologists Basil Bernstein and Pierre Bourdieu, including Bernstein's code theory, knowledge structures and pedagogic device, and Bourdieu's concepts of field theory, capital and habitus (for a more detailed account of the develop of LCT, see Maton 2014b). LCT comprises five dimensions, but for the purposes of this paper we focus on the dimension of Semantics. Concepts from the Semantics dimension of LCT provide some useful tools to think about physics knowledge structure and to analyse physics pedagogical practices. The two concepts from the dimension of Semantics used as a conceptual framework in this study are semantic gravity and semantic density.

Semantic gravity is defined as the extent to which meaning 'is related to its context of acquisition or use' (Maton 2009: 46). When semantic gravity is weaker, meaning is less dependent on its context. Physics operates with abstract, decontextualised concepts and principles, which have weaker semantic gravity. These abstract principles can then be applied to a variety of specific physics contexts, with stronger semantic gravity. For example, abstract physics concepts (such as 'force' or 'energy') can be used in a wide range of specific contexts, ranging from small atoms to vast galaxies.

Semantic density is defined as the extent to which meaning is concentrated or condensed within symbols (a term, concept, phrase, expression, gesture, etc.) (Maton 2014b). Physics works with stronger semantic density, because meaning is condensed within nominalisations (that is, scientific words or phrases that are dense in meaning), for example, 'constant acceleration' or 'induction'. Meaning is also condensed within the multiple representations (for example, graphs, symbols, diagrams, mathematical formulae) that characterize the discipline.

To visualise the relative strengths of semantic gravity and semantic density (SG and SD) over time, Maton (2014b) has developed an analytical method of semantic profiling. This indicates in the form of a diagram how the strengths of SG and SD vary over time. The strengths of SG and SD are represented on the $y$-axis, with time on the $x$-axis. In the semantic profile, SG and SD are mostly portrayed as inversely related. However, this conflation of SG and SD may not always apply, and in such cases, representing SG and SD on 
a semantic plane, or quadrant, is more useful, where SG and SD vary independent of each other (see Maton 2014b; Blackie 2014, for a chemistry example).

The semantic profile can be used to map practices as they unfold in time, whether in a student task (e.g., an essay or problem task), a single classroom episode, part of a lesson, a series of lessons, an entire course or even a whole curriculum. Semantic profiles can also be characterized as having a 'fractal application' (Maton 2014a: 44): as one moves towards a more macrolevel (e.g., from a classroom episode to a whole lesson), waves within waves become evident. For example, a semantic 'upshift' in a lesson may comprise several smaller up and down semantic waves within the overall 'upshift'.

Figure 1 shows three different semantic profiles: if these corresponded to three different lessons, then A1 would indicate a lesson in which the teaching remain at the abstract level (SG-), for example, a description of Newton's Second Law condensed in mathematical representations (SD+); A2 would indicate a lesson that remained at the concrete level (SG+), for example, describing the motion of common objects in everyday language; B would represent what Maton terms a 'semantic wave', which indicates shifts between context-dependence (from concrete examples of everyday objects to abstract principles) and the condensation of meaning (verbal descriptions of motion condensed into mathematical formalism). Profile B is said to have a greater 'semantic range' than either A1 or A2.

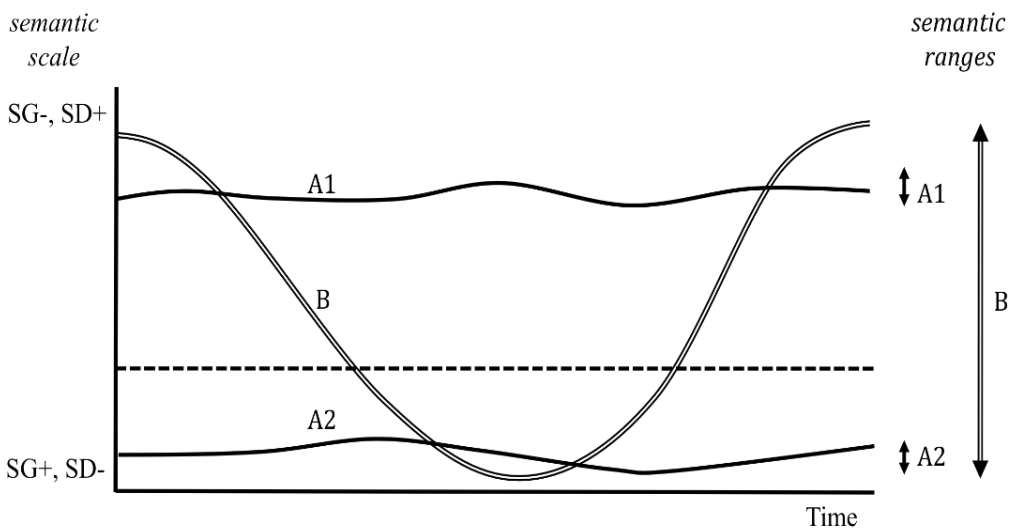

Figure 1. Diagram of semantic profiles and ranges (Maton 2013:13). 
Maton (2013) argues that cumulative learning is enabled through this variation in strengthening and weakening of semantic gravity and semantic density with time. 'Upshifting' indicates where theorizing is emphasized, and where applications are used to build towards theory. Maton argues that in a pedagogical practice, there should be both 'downshifting and upshifting', and 'unpacking and repacking' of the concepts, in order to relate 'technical concepts to everyday examples' and to 'condense meaning to abstract theoretical ideas' (Maton 2014b:192). One weakness of this cumulative learning perspective is that it may take for granted the social and cultural embeddedness of 'everyday examples'. For example, common examples given in university physics textbooks of low friction surfaces are those of skiing or ice hockey, both with little relevance to most South African students.

However, with this caveat in mind, these LCT tools have proven useful in a wide range of disciplinary contexts for analyzing teaching practices and for assisting both academic development practitioners and discipline lecturers to improve pedagogical practices in higher education (see for example, Clarence 2016 \& 2017; Blackie 2014). In this study of physics and mathematics pedagogical practices, the LCT theoretical tools were well-suited to characterizing the movement between abstract principles and concrete contexts that is entailed in physics pedagogy, as well as the ways in which meaning is encapsulated in the dense representations used in physics and mathematics.

In the next section, we draw on these concepts from LCT to construct semantic profiles of pedagogical practices in first and second year lectures. In this way, LCT was useful for examining the pedagogical practices that enable or hinder the transition to second year.

\section{Research Methods}

The broad aim of the study was to develop a fuller understanding of students' experiences of the crucial transition from the ECP to their second year courses. A starting point was to build an understanding of how the pedagogical practices of ECP and second year courses were related. This section describes the analytical framework, and how data was collected and analysed.

\section{Developing an Analytical Framework}

Bernstein (2000) introduced the notion of 'external language of description' as 
a way of understanding the form taken by theory. An 'external language of description' offers a way of translating between theoretical concepts and empirical data, in order to show how concepts are utilized for a particular research context. In this study, the external language of description works as a sort of analytical framework, relating the concepts of 'semantic gravity' and 'semantic density' to the context of undergraduate physics. This framework draws on the work of Lindstrom (2010) and Georgiou (2012), who have presented ways of coding the relative strengths of semantic gravity in the context of physics lectures and students' responses to physics tasks. They use the label abstract to refer to statements of general principles or laws; concrete refers to a description of the characteristics of everyday objects; and intermediate (or linking) refers to instances where abstract and concrete constructs are linked. Table 1 below describes the external language of description for semantic gravity and semantic density used in this study to characterize pedagogical practices.

\begin{tabular}{|c|c|c|c|c|}
\hline Strength & SG & & SD & Strength \\
\hline SG- & New concepts & $\begin{array}{c}\text { Abstract } \\
\text { A }\end{array}$ & $\begin{array}{l}\text { Representations (or } \\
\text { nominalisations) }\end{array}$ & $\mathrm{SD}+$ \\
\hline & $\begin{array}{l}\text { Familiar concepts } \\
\text { used in a linking } \\
\text { way }\end{array}$ & $\begin{array}{c}\text { Linking } \\
\text { (Intermediate) } \\
\text { L }\end{array}$ & $\begin{array}{l}\text { Unpacking or } \\
\text { repacking } \\
\text { representations }\end{array}$ & $\downarrow$ \\
\hline SG+ & $\begin{array}{l}\text { Concrete/real-life } \\
\text { situations }\end{array}$ & $\begin{array}{c}\text { Concrete } \\
\text { C }\end{array}$ & $\begin{array}{l}\text { Linking } \\
\text { representations to } \\
\text { concrete situations }\end{array}$ & SD- \\
\hline
\end{tabular}

Table 1. External language of description for semantic gravity and semantic density 
The strengths of SG and SD were characterized as Concrete, Linking or Abstract, depending on the lecturers' actions and way of unfolding the concepts. At the Concrete level, semantic gravity is stronger: here the lecturer would be referring to a concrete situation or demonstration in class. At the same time, the semantic density would be weaker: representations would be unpacked and linked to the concrete situation usually in the form of a verbal representation. At the Abstract level, semantic gravity would be weaker: here the lecturer would be using new physics concepts or principles, mostly represented in semantically denser modes (graphical, diagrammatic or mathematical representations). The Linking level is characterized by the lecturer building on familiar concepts or principles in a linking way, between Concrete and Abstract; here, dense representations were being explicitly unpacked or repacked into their constituent parts or meaning.

\section{Data Collection and Analysis}

The first part of the study examines the pedagogical practices in the ECP course. Data was drawn from observation field notes and video-recordings of lectures. These were transcribed, capturing the audio data as well as all visual data (gestures used, writing on the board, etc.). As a form of data reduction (Miles \& Huberman 1994), summaries of the transcriptions were prepared. Semantic profiles were constructed to map movement between abstract principles and concrete contexts in the teaching as well as the ways in which representations were used during each lecture. On the semantic profiles, coding (in the form of line thickness) is used to indicate the different forms of interaction in lectures (with a thin line indicating where only the lecturer is talking, and a thick line indicating lecturer-student interactions and engagement). In this way distinctive features of the ECP pedagogy were drawn out. Of the many lecture sequences observed and recorded, one is presented in this paper.

The second part of the study examined the pedagogical practices of a second year physics course (Classical Mechanics), and a related mathematics course (Advanced Calculus). For the second year courses, the data was in the form of field notes, rather than video data. This was because the analytical framework had been developed through a fine-grained analysis of the ECP data. Semantic profiles were constructed for the second year lectures; although these were not as fine-grained as the first year lectures, they captured the broad 
shifts between abstract and concrete in the lectures. As noted in LCT research, semantic profiles are a useful heuristic device suited both for fine-gained discourse analysis of short classroom episodes, or for less fine-grained mapping of larger lecture sequences (see, for example, Clarence 2017; MacNaught et al. 2013). In conducting the classroom observations, developing a relationship of trust with the lecturers was key. One of the authors worked closely with the lecturers, firstly as an academic development practitioner with the physics ECP lecturers (see Marshall et al. (2010) for an account of this collaboration), and later as a Teaching and Learning specialist working alongside the second year lecturers.

In considering the validity of the data analysis, we draw on the concept of credibility (Lincoln \& Guba 1985), more suited to qualitative research. Through 'prolonged engagement' (Lincoln \& Guba 1985), many lectures were observed in each of the courses analysed, and the example lecture sequences presented here are representative of the teaching approaches in the other lectures observed. Another approach to ensuring credibility is what Lincoln \& Guba (1985) term 'peer debriefing': here, the construction and analysis of the semantic profiles was shared with colleagues and with the lecturers themselves.

The third source of the data collected was interviews conducted with twelve second year students. The interviews were open-ended in structure, encouraging students to reflect on their experiences of the transition from the ECP to second year.

\section{Research Findings: Analysis of Pedagogical Practices in ECP and Second Year Classes}

In this section, we use tools from LCT to analyse the pedagogical practices in ECP and second year courses as a means to develop insights into the challenges students face in making the transition to second year.

We start with a brief analysis of pedagogical practices in the ECP, as a way to understand the learning experiences of ECP students. The data for this section is drawn from a larger study on ECP pedagogical practices in an introductory physics course (Conana 2016). As space is limited, this section merely provides a brief overview of distinctive features of the ECP pedagogical practices, and includes some illustrative examples to exemplify the discussion. 
The analysis then turns to the pedagogical practices in the second year physics and mathematics courses. Using LCT as a theoretical lens, we identify certain key mismatches in pedagogical practices between the ECP and second year courses. These may shed light on the difficulties with transition that many students face.

\section{Part 1: Analysis of Pedagogical Practices in ECP}

A larger study of the pedagogical practices in the ECP course, framed using concepts from LCT, revealed the following distinctive features of the ECP pedagogy (Conana, 2016; Conana, Marshall \& Case, in press):

- Pacing: In keeping with the extra time allocated, the pacing at the outset of the ECP was slower, allowing time for foundational additions. Towards the end of the ECP course, the pacing increased to be more consistent with the mainstream pacing.

- Semantic range: The ECP showed a large semantic range (between Abstract and Concrete), with more time spent at the Linking level, and frequent shifts to the Concrete level

- Representational modes: A range of representational modes were used during the lectures, including concrete demonstrations and gestures, sketches, force diagrams, graphs and mathematical equations

- Interactive engagement: student engagement in class was a common feature of all ECP lectures.

As an illustrative example, we present an analysis of one of the ECP lecture sequences (see Figure 2 below), to exemplify these features:

This lecture sequence took place towards the end of the first year, when the pacing had increased to be consistent with the pacing of the mainstream first year course. The topic here was Energy, and the physics concepts of 'conservation of energy' and 'conservative forces' were introduced. This was a sequence of two lectures of 60 minutes each.

The semantic profile in Figure 2 shows a large semantic range (moving between Abstract and Concrete), including frequent shifts to the Concrete level. The lecturer starts at the Linking level by eliciting students' prior knowledge about energy (from time 0-5 minutes). The students reply with variations of the familiar definition from school, "energy cannot be created or 
destroyed, but it can be transferred or transformed from one form the another'. The lecturer then unpacks the meaning of the terms 'transferred' and 'transformed' and relates this definition to a concrete demonstration (lifting a pen up above his head), to discuss concepts of potential energy and then linking this to the concept of 'work done'.

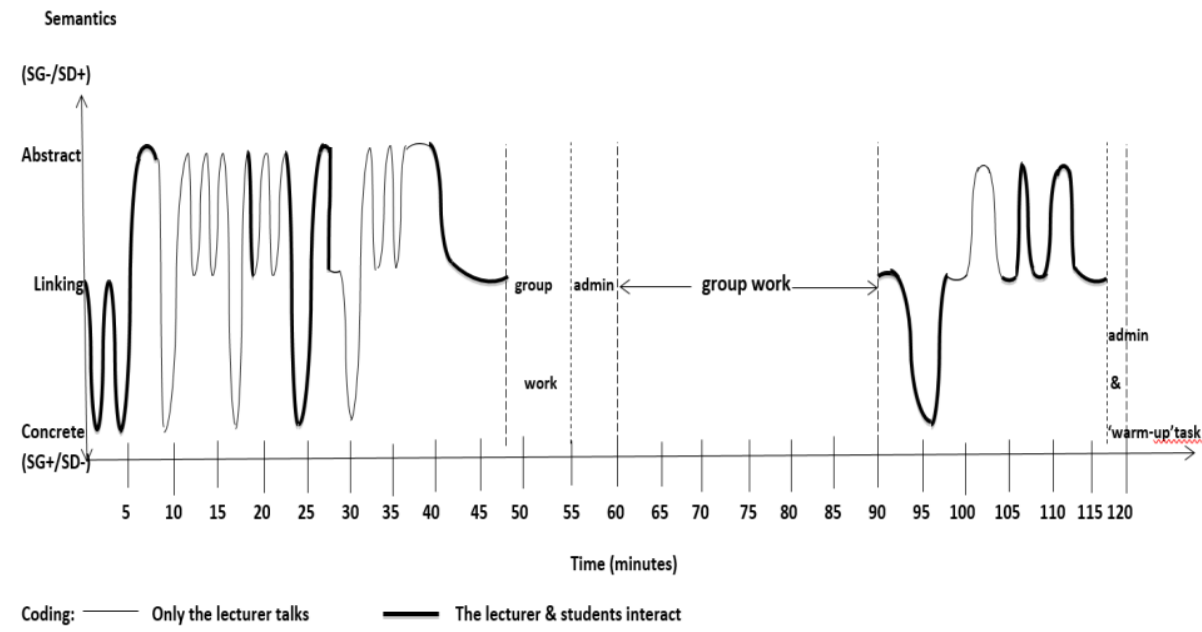

Figure 2: Semantic profile of a lecture sequence in an ECP physics course

In terms of the LCT concept of 'semantic waving' introduced early, the semantic profile in Figure 2 shows frequent movement up and down the semantic continuum ('downshifting and upshifting') in the lecture sequence, with explicitness in explaining and condensing ('unpacking and repacking') the concepts. This semantic waving is well-illustrated in the period 8-16 minutes on the semantic profile: the lecturer introduces the abstract concept of 'conservative forces', and then shifts down the semantic continuum to demonstrate this with a concrete example (moving his pen up and down). He then repacks this concrete example in theoretical terms relating to losses and gains in energy. From here, he abstracts further to the concepts of 'conservation of energy' and a 'conservative force'. From this Abstract level, he then shifts down again to the Concrete level and unpacks the concept of conservative force 
using a different example, this time a spring oscillating up and down. From this more concrete example, we then see condensation of meaning occurring, as the lecturer shifts up the semantic continuum, moving from the demonstration and verbal description of an oscillating spring, to a sketch of the spring and then to a symbolic representation of the potential energy of the spring. This episode in the lecture points to the explicit use of a range of representational modes in the teaching, shifting between demonstrations, sketches, diagrams and mathematical symbols.

Finally, the semantic profile shows that student engagement was an important feature of the lecture: the line thickness coding on the semantic profiles indicates the many times during the lecture when there is student engagement, and a considerable amount of time is given for groupwork during classtime. After the first lecture, students complete a homework task (calculating the work done by a traveller carrying a suitcase up a flight of stairs). In the second year lecture, the first 30 minutes (from 60-90 minutes on Figure 2) is given to consolidating and discussing their solutions in groups, after which the lecturer discusses the problem and gives feedback. The lecturer starts at the Linking level with unpacking the problem statement with the students, then moves to a concrete enactment of the problem situation (he mimes carrying a suitcase). Through a process of building on students' solutions, he sketches the situation (to model the situation to capture the important features of the problem), represents the problem as a force diagram (identifying the key forces on the suitcase, and translating words to symbols), and finally represents the situation in a mathematical representation. The line-thickness coding during this period (from 90 - 115 minutes) indicates that the students themselves were engaged in enacting these semantic shifts between representations.

In summary, the ECP pedagogy was characterized by a large semantic range (between Abstract and Concrete levels), frequent 'semantic waving' up and down the semantic continuum, a wide use of representational modes (and explicit unpacking and repacking of these), and interaction engagement during lectures.

\section{Part 2: Analysis of Pedagogical Practices in Second Year Classes} The second part of the analysis looked at the pedagogical practices in the second year physics (Classical Mechanics) and mathematics (Advanced 
Calculus) classes. The purpose of the analysis was to understand students' experiences in second year and the challenges students and staff faced. The data collected was in the form of classroom observation notes rather than video-data (to be less intrusive in these classes) and so it should be noted that the semantic profiles are not as fine-grained as in the ECP case. Nevertheless they fulfill a useful heuristic role in characterizing the overall semantic shifts in the lectures.

The analysis started with the Physics course, since this was a logical progression from the ECP Physics module the previous year. The semantic profile of a second year physics lecture is presented in Figure 3.

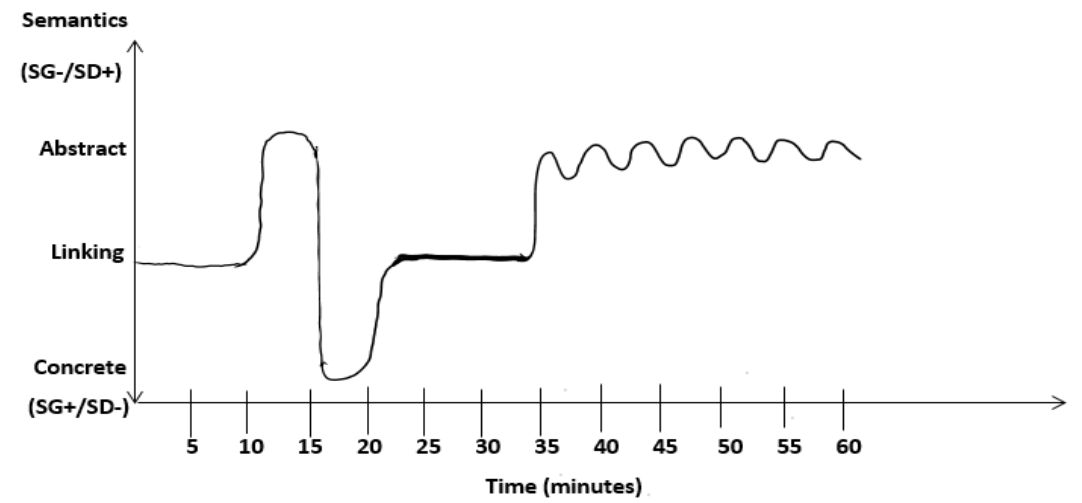

Coding: - Only the lecturer talks

The lecturer \& students interact

\section{Figure 3: Semantic profile of a lecture in a second year physics course}

At the start of the lecture, the lecturer introduces a problem situation at the Linking level, drawing on first year physics principles and linking to the first year mathematics concept of integration (from about time 0 to 10 minutes). He senses that the students are not following his explanations, and so responds to this by moving from the abstract concept of 'integration' to a concrete, illustrative example (at about minute 15). Here, the graphical representation of integration (taking the sum over smaller and smaller pieces under a graph) is related to an analogy of a sliced loaf of bread, and students are then given time (from about minute 20 to 35 ) to discuss the situation and work on representing the problem situation as a mathematical function. 

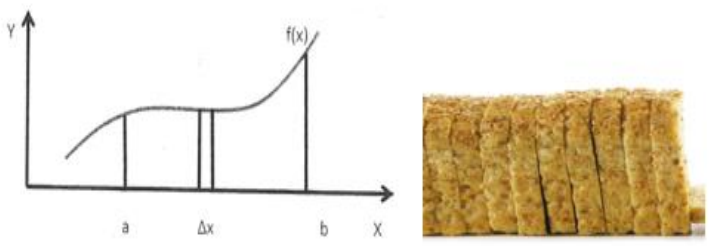

\section{$\int_{a}^{b} f(x) d x=\lim _{\Delta x \rightarrow 0} \sum f\left(x_{i}\right) \Delta x$}

Figure 4: Representations used in the second year physics course: graphical representation, sliced bread analogy, mathematical formalism

During the remainder of the lecture, the lecturer explains the advanced calculus in the problem and the explanation remained mostly at the Abstract level, moving between principles, and graphical and mathematical representations.

As noted earlier, one of the authors had been working with the physics lecturer in order to understand students' difficulties with second year physics. It was evident that students were struggling to use the mathematical principles and procedures of integral calculus in the physics course, and so the research interest turned to students' experiences of learning integral calculus in their second year Advanced Calculus course.

The semantic profile in Figure 5 gives an overview of the semantic range used in a representative Advanced Calculus mathematics lecture. At the start of the lecture, the lecturer introduces a problem situation at the Linking level, drawing on simple integration principles from first year mathematics. He then moves to a calculation of surface area using double integrals, and at this point the lecture is mostly at the Abstract level, using abstract diagrams and mathematical formalism. The students follow the notes presented and there is no interactive engagement.

In summary, the second year Physics and Mathematics pedagogy was characterized by a smaller semantic range than the ECP pedagogy, and less semantic waving than in the ECP pedagogy. The second year Physics lecture began with a useful concrete example on which to build toward mathematical abstraction; the Mathematics lecture remained predominantly at the Abstract level. While the ECP pedagogy explicitly incorporated a range of representational modes (and students actively engaged in the unpacking and repacking of these), in the second year pedagogy, there was less variation of representational modes. The Physics lecture included variation in representational modes gestures, text, analogy, diagrams, and mathematical formalism; in the Mathe- 
matics lecture, the representations used were mostly abstract diagrams and mathematical formalism. As might be expected in senior level courses, there was less interactive engagement than in the ECP pedagogy, although the responsiveness of the Physics lecturer to student difficulties was evident with the inclusion of the concrete example in the lesson.

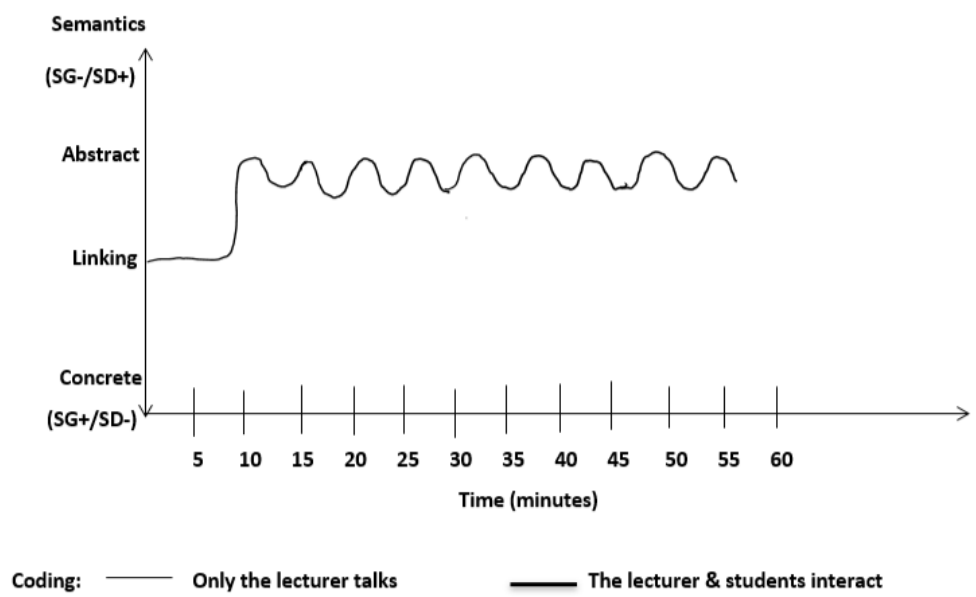

\section{Figure 5: Semantic profile of a lecture in a second year mathematics course}

\section{Part 3: Students' Experiences of the Transition to Second Year}

Interviews with twelve students in the mathematics course about their experiences of the transition to second year reflected some of the pedagogical issues that the LCT analysis of pedagogical practices had highlighted.

Firstly, the students noted the difference in pacing, especially in the Mathematics course. This student notes that concepts are introduced very quickly in class, with the expectation that students will work through the notes and exercises at home:

In the second year maths, it's all about what you have to do at home, what you do for yourself .... You have to learn it very quickly, and absorb it very quickly as well. When you advance to second year maths, 
you just get a shock. This year, in second year maths, the lecturer just reads the notes and explains a few concepts and just - you need to do it all at home. There's no time [as in the ECP] that you have to work on something for weeks, it's just about what you are doing at home.

Similarly, another student describes a sense of feeling overwhelmed by trying to keep up to date with the pace of the class:

I feel like there's lots of gaps this year. You have to constantly go back, which is, you have to do the stuff everyday in order to get it. But the more you go back, the more you fall behind and the more you create more gaps for yourself. Unless you can work very fast, your time will fall short. This year, it is all about how you use your time. In first year, it wasn't like this. When we started with second year, it was like 'Boom!' They were all throwing things on us, it is so overwhelming.

Although the students did not explicitly talk about semantic range, their comments reflected their experiences of moving to more abstract, theoretical courses. Some described experiencing a lack of perceived relevance due to the increased abstraction:

I've lost my motivation this year - it's just theory.

There's something missing in terms of what is happening, this year. I've lost that 'Oomph' in Maths.

The students miss the explicitly building on their prior knowledge, which was more prevalent in the ECP pedagogy:

I can't see the links between what I'm doing here and last year. The way it is presented makes us think there is no connection.

Their comments also reflected the observation in the LCT analysis that a more restricted range of representational modes was used: while the ECP used a range of different representations, the second year lectures were more mathematically-focused. This is to be expected in senior physics and mathematics courses. However, what the students particularly noted was that 
representations with stronger semantic density were often taken for granted and not explicitly unpacked in the teaching:

The problem is, now everything is abstract. We have to picture these problems. I struggle to visualise them. I tried to, but you have to capture all these concepts visually.

What's the purpose of sketching if I can't visualise what I'm drawing? It's very complicated.

Students describe how lecturers use representations, such as graphs, but don't explicitly help students to discern the important features and unpack the meaning:

Our lecturers teach us how to draw graphs but never teach us how to view them... I have a lot of sketches in my notebook that I still don't understand.

Working from $2 \mathrm{D}$ to $3 \mathrm{D}$, it's a huge difference. So, you have to constantly translate how you did maths in 2D and transform it to 3D. And the problem now is that there is too much to visualise and it is graphical. But at the beginning, like taking and understanding limits from $2 \mathrm{D}$ to $3 \mathrm{D}$ is different. It's just there's a lot of things you have to keep in mind, the concepts just build up.

Finally, students miss the interactive engagement in class that was a common feature of all ECP lectures. Students noted that the fast pace precluded much interaction with lecturers:

Our lecturers are not interacting with us....They are so fast, they are just running with the notes.

Students also missed the groupwork approach which was fostered in the ECP:

It would be much better if we could work in groups, like in first year because you can work with someone else than working on your own, it was more effective. 
We are not interactively doing the work in class, most of us we are doing the work at home alone. I feel like we should do group-work.

\section{Discussion}

Using tools from the Semantics dimension of LCT, this study has highlighted some of the difficulties that students experience in the transition from an extended curriculum programme into second year. The analysis suggests that this transition may be exacerbated by some differences or discontinuities in pedagogical practices between the ECP and the second year.

Firstly, the pacing of the ECP is slower, and students struggle with the inevitable increase in pace in the second year. They note how they sometimes feel overwhelmed at the amount of new concepts and the expectation that so much of the learning will take place at home.

Secondly, the semantic range in the pedagogical practice diminishes with the transition to second year. In ECP, the semantic range is large (spanning Abstract and Concrete), with more time spent at the Linking level, and frequent shifts to the Concrete level. By contrast, the semantic range of the second year Physics and Mathematics courses was more narrow, predominantly at the Abstract level, which is to be expected in these more advanced courses. Some students experienced a lack of relevance due to the increased abstraction, which led to some describing a deflated sense of motivation. Students also struggled to link the concepts being dealt with in second year to their prior knowledge from first year.

Thirdly, the range of representational modes used in the second year narrowed. In the ECP, a range of representational modes were used during the lectures (concrete demonstrations and gestures, sketches, force diagrams, graphs and mathematical equations), whereas the second year lectures relied far more on the mathematical representations that inevitably become more prevalent in advanced courses. Students noted that there was far less explicit unpacking and repacking of semantically dense representations, such as graphs or diagrams, in the second year courses. This was evident in less semantic waving in the second year semantic profiles.

Lastly, interactive engagement was clearly a key aspect of the ECP pedagogical practices which was less common in much of the second year pedagogy. Students noted how they missed this form of interaction and would have welcomed more structured groupwork in their second year classes. 
In summary, the LCT analysis - complemented with data from student interviews - highlights the mismatches between the ECP and second year pedagogical practices. These include: increased pacing, a curtailed semantic range concentrated more at the Abstract level, less 'semantic waving', a narrower range of representations used, and less interactive engagement between students and lecturer. Some of these aspects of pedagogical practices are also noted by Ellery (2017) in her Bernsteinian analysis of the transition to mainstream in a science extended curriculum programme, in particular increased pacing, high volumes of work at a high conceptual level, and less rapport with teaching staff.

\section{Implications and Concluding Remarks}

Much research on foundation provision in South Africa has focused on the transition from school to first year, and less so on the transition to second year or the other 'epistemic transitions' throughout the undergraduate degree. This study addresses this paucity in the literature of research on the transition to second year. The findings support previous arguments that foundational provision needs to extend beyond the first year of a programme (for example, Rollnick 2010; CHE 2013).

In the transition to second year physics and mathematics courses, an increase in abstraction and mathematical rigour is inevitable. However, the findings suggest that students still require a greater semantic range in the pedagogical practices, with more time spent unpacking dense representations and linking back to concrete examples wherever feasible. As Georgiou (2014) notes, in the context of physics learning, the 'connectivity' between abstract and concrete is not only associated with students' deeper understanding of physics concepts, but also with improved student engagement and positive attitudes towards physics. For some students, the lack of 'connectivity' between abstract and concrete with the increased abstraction at second year led to experiences of lack of relevance and demotivation. Students felt the load of many new concepts not familiar from high school or first year (which seems a common second year experience, as noted by Milsom \& Yorke 2015). In this regard, they missed the more explicit linking to their prior knowledge which had been a key feature of the ECP pedagogy.

The findings also suggest that second year pedagogical approaches in physics and mathematics ought to continue to focus more deliberately on the 
use of representations. Accessing a disciplinary discourse takes time and is a process that doesn't end at the first year. As Eriksson et al. (2014) note, students' mastery of disciplinary representations develops over an extended period of time. Yet, lecturers are often so familiar with disciplinary representations that they take these for granted, and 'no longer 'notice' the learning hurdles involved in interpreting the intended meaning of these representations' (Fredlund et al. 2014: 020129-4). This suggests that the careful 'unpacking' and 'repacking' of dense representations used in mathematics and physics is crucial for learning, even in second year. This is borne out in other studies that suggest that explicit focus on representations in a 'representation-rich learning environment' (Rosengrant et al. 2009:0101082) supports student learning and hence enables epistemological access.

Perhaps the most notable mismatch in pedagogical practices between the ECP and the second year courses was the reduction of interactive engagement, particularly in the mathematics course. This contrasted with the ECP pedagogy, which had fostered the development of a 'classroom community' in which students often worked together and supported each other in class and outside of class. While it might be argued that the more advanced content in senior level courses limits the time for interactive engagement, physics education literature has shown that student engagement is critical for undergraduate science learning (Hake 1998; Mazur 2009; Wieman \& Perkins 2005), and that interactive engagement is possible to implement even in senior level courses (for an example in quantum physics, see Singh \& Zhu 2011). Besides the cognitive learning benefits, research also shows how groupwork and other social learning approaches have important affective benefits, helping students in developing social networks and supporting each other (see, e.g., Tinto 1997).

In conclusion, tools from Legitimation Code Theory (LCT) proved useful in analysing the pedagogical practices in ECP and second year courses as a means to develop insights into the challenges students face in making the transition to second year. The findings suggest that attentiveness to particular pedagogical aspects (pacing, semantic range, representational modes and interactive engagement) is likely to support students in accessing the disciplinary knowledge and in navigating the 'epistemic transition' to second year. However, as Clarence (2017) notes, the LCT analytical tools are useful not only for analysis of pedagogical practices, but they are also useful for academic staff development. As described earlier, one of the authors had been working alongside the second year lecturers in a staff development role. One 
of the outcomes of sharing the findings of this study has been greater collaboration between the departments of physics and mathematics in terms of horizontal and vertical curriculum alignment. This has led to some changes in pedagogical practice at the second year level (including more semantic waving and more interactive engagement), which have led to significant improvement in student learning (see Conana, Solomons \& Marshall 2019). This collaboration has also led to the fostering of a more holistic approach to undergraduate science teaching, focusing on the 'whole student' rather than just STEM knowledge and skills (Winberg et al. 2018).

As a final point, we return to Moje's (2007) useful distinction between socially just pedagogy and pedagogy for social justice. A pedagogy that makes the disciplinary discourse more explicit (through attention to semantic range, representational modes and interactive engagement) can be viewed as socially just pedagogy, since the focus is on inducting students into the specialized (socalled 'powerful') knowledge of the discipline and attending to the 'epistemic transition' to second year. In this paper, we have largely focused on the role of pedagogical practices in inducting students into disciplinary discourses. However, pedagogy that makes room for more interactive engagement would also create the space for adopting a more critical perspective on scientific knowledge itself. This could include exploring the wider social, ethical and environmental aspects of science, and allow for greater responsiveness to students' own lives and concerns, to counter student experiences of science as alienating and decontexualised. This then, would also enable a pedagogy for social justice, and open up the space for more transformative approaches to foundational provision.

\section{References}

Airey J. \& C. Linder. 2009. A Disciplinary Discourse Perspective on University Science Learning: Achieving Fluency in a Critical Constellation of Modes. Journal of Research in Science Teaching 46: 27 - 49. https://doi.org/10.1002/tea.20265

Bernstein, B. 2000. Pedagogy, Symbolic Control and Identity: Theory, Research, Critique. Revised Edition. Oxford: Rowman \& Littlefield. Bing, T.J. \& E.F. Redish 2009. Analyzing Problem Solving Using Math in Physics: Epistemological Framing via Warrants. Physical Review Special Topics - Physics Education 5: 020108. 
https://doi.org/10.1103/PhysRevSTPER.5.020108

Blackie, M. 2014. Creating Semantic Waves: Using Legitimation Code Theory as a Tool to Aid the Teaching of Chemistry. Chemistry Education Research and Practice 15: 462 - 469.

https://doi.org/10.1039/C4RP00147H

Boughey, C. 2010. Understanding Teaching and Learning at Foundation Level:

A 'Critical' Imperative? In Hutchings, C. \& J. Garraway (eds): Beyond the University Gates: Provision of Extended Curriculum Programmes in South Africa. Rhodes University: HELTASA.

Bruner, J. 1960. The Process of Education. Cambridge, MA: Harvard UP.

Carstens, D. 2016. The Anthropocene Crisis and Higher Education: A

Fundamental Shift. South African Journal of Higher Education 30, 3: 255

- 273. https://doi.org/10.20853/30-3-650

Clarence, S. 2016. Exploring the Nature of Disciplinary Teaching and Learning using Legitimation Code Theory Semantics. Teaching in Higher Education 2, 2: 123 - 137.

https://doi.org/10.1080/13562517.2015.1115972

Clarence, S. 2017. Surfing the Waves of Learning: Enacting a Semantics Analysis of Teaching in a First Year Law Course. Higher Education Research and Development 36, 5: 920 - 933.

https://doi.org/10.1080/07294360.2016.1263831

Cobern, W.W. 1998. Science and the Social Constructivist View of Science Education. In Cobern, W.W. (ed.): Socio-cultural Perspectives in Science Education. Dordrecht: Kluwer. https://doi.org/10.1007/978-94-011-52242

Collier-Reed, B., K. le Roux \& M. Rollnick 2010. Editorial: Using Discourse and Identity to Conceptualise Learning in Tertiary Science and Engineering. African Journal of Research in Mathematics, Science and Technology Education 14, 2: 6 - 12.

https://doi.org/10.1080/10288457.2010.10740677

Conana, H. 2016. Using Semantic Profiling to Characterize Pedagogical Practices and Student Learning: A Case Study of Two Introductory Physics Courses. Unpublished $\mathrm{PhD}$ thesis, University of the Western Cape.

Conana, H., D. Marshall \& J. Case 2016. Exploring Pedagogical Possibilities for Transformative Approaches to Academic Literacies in Undergraduate Physics. Critical Studies in Teaching and Learning 4, 2: 28 - 44. 
Conana, H., D. Solomons \& D. Marshall 2019. Supporting the Transition from First to Second Year Mathematics Using LCT Research Findings. Paper presented at The Third International Legitimation Code Theory Conference (LCT3), Johannesburg, South Africa, July 2019.

Conana, H., D. Marshall \& J. Case (in press). A Semantics Analysis of First Year Physics Teaching: Developing Students' Use of Representations in Problem-solving. In Winberg, C., S. McKenna \& K. Wilmot (eds.): Building Knowledge in Higher Education: New Directions in Teaching and Learning. London: Routledge.

Council on Higher Education (CHE) 2013. A Proposal for Undergraduate Curriculum Reform in South Africa: The Case for a Flexible Curriculum Structure. Report of the Task Team on Undergraduate Curriculum Structure. Available at:

http://www.che.ac.za/media_and_publications/research/proposalundergr aduate-curriculum-reform-south-africa-case-flexible. (Accessed on 22 April 2017.)

Council on Higher Education and South African Institute of Physics (CHESAIP) 2013. Review of Undergraduate Physics Education in Public Higher Education Institutions. Available at:

http://www.saip.org.za/images/stories/documents/Reports/Undergrad_Ph ysics_Report_Final -1.pdf (Accessed on 22 April 2017.)

Doran, Y. 2016. Knowledge in Physics through Mathematics, Image and Language. Unpublished $\mathrm{PhD}$ thesis, University of Sydney.

Elley, K. 2017. Framing of Transitional Pedagogical Practices in the Sciences: Enabling Access. Teaching in Higher Education 22,8: 908 - 924. https://doi.org/10.1080/13562517.2017.1319812

Engelbrecht J, Harding A. \& P. Phiri 2010. Are OBE Trained Students Ready for University Mathematics? Pythagoras 72: 3-13.

https://doi.org/10.4102/pythagoras.v0i72.16

Etkina, E. \& A. van Heuvelen 2007. Investigative Science Learning Environment: A Science Process Approach to Learning Physics. In Redish, E.F. \& P. J. Clooney (eds.): Research-based Reform of University Physics. Compadre: American Association of Physics Teachers.

Eriksson, U., C. Linder, K. Airey \& A. Redfors 2014. Introducing the Anatomy of Disciplinary Discernment: An Example from Astronomy. European Journal of Science and Mathematics Education 2:167 - 182. iL

Fredlund, T., C. Linder, J. Airey \& A. Linder 2014. Unpacking Physics 
Representations: Towards an Appreciation of Disciplinary Affordance. Physical Review Special Topics - Physics Education 10: 020129. https://doi.org/10.1103/PhysRevSTPER.10.020129

Gee, J.P. 2005. An Introduction to Discourse Analysis: Theory and Method: $2^{\text {nd }}$ Edition. London: Routledge.

Georgiou, H., K. Maton \& M. Sharma 2014. Recovering Knowledge for Science Education Research: Exploring the 'Icarus Effect' in Students Work. Canadian Journal of Science, Mathematics and Technology Education 14,13: 252 - 268.

https://doi.org/10.1080/14926156.2014.935526

Grayson D. J. 2010. Design of the Engineering Augmented Degree Programme at the University of Pretoria. ASSAf Mind the Gap Forum October 2122; Cape Town, South Africa.

Hake, R. 1998. Interactive-engagement versus Traditional Methods: A Sixthousand Student Survey of Mechanics Test Data for Introductory Physics Courses. American Journal of Physics 66,1: 64 - 74. https://doi.org/10.1119/1.18809

Hugo, W. 2016. Think Piece: What Education is of Most Worth in a World where we are Consuming the Future of our Children? Southern African Journal of Environmental Education 32:11 - 25.

Hunter, M.S., B.F. Tobolowsky, J.N. Gardner, S.E. Evenbeck, J.A. Pattengale, M.A. Schaller \& L. Schreiner (eds.). 2010. Helping Sophomores Success: Understanding and Improving the Second Year Experience. San Francisco, CA: Jossey-Bass.

Jacobs, C. 2007. Towards a Critical Understanding of the Teaching of Discipline-specific Academic Literacies: Making the Tacit Explicit. Journal of Education 41: 59 - 81.

Kloot, B., J.M. Case \& D. Marshall 2008. A Critical Review of the Educational Philosophies Underpinning Science and Engineering Foundation Programmes. South African Journal of Higher Education 22,4: 799 - 816. https://doi.org/10.4314/sajhe.v22i4.25817

Kress, G. 2010. Multimodality. A Social Semiotic Approach to Contemporary Communication. London: Routledge Falmer.

https://doi.org/10.4324/9780203970034

Lemke, J.L. 1990. Talking Science: Language, Learning and Values. London: Albex Publishing.

Lillis, T. \& M. Scott 2007. Defining Academic Literacies Research: Issues of 
Epistemology, Ideology and Strategy. Journal of Applied Linguistics 4,1:

5 - 32. https://doi.org/10.1558/japl.v4i1.5

Lindstrøm, C. 2010. Link Maps and Map Meeting: A Theoretical and Experimental Case for Stronger Scaffolding in First Year University Physics Education. Unpublished $\mathrm{PhD}$ thesis, University of Sydney.

Lubben, F.E. 2007. Success through the General Entry Programme for Science (GEPS): Reflections by GEPS Students in their Third Year at UCT. Report to the Academic Development Programme, University of Cape Town.

Marshall, D. \& J. Case 2010. Discourse in the Learning of Physics: The Design of an Introductory Physics Curriculum. African Journal of Research in Mathematics, Science and Technology Education 14,2: 6 - 12.

https://doi.org/10.1080/10288457.2010.10740679

Marshall, D., H. Conana, R. Maclons, M. Herbert \& T. Volkwyn 2011. Learning as Accessing a Disciplinary Discourse: Integrating Academic Literacy into Introductory Physics through Collaboration Partnership. Across the Disciplines 8,3.

Maton, K. 2009. Cumulative and Segmented Learning: Exploring the Role of

Curriculum Structures in Knowledge-building. British Journal of Sociology of Education 30,1: 43 - 57.

https://doi.org/10.1080/01425690802514342

Maton, K. 2013. Making Semantic Waves: A Key to Cumulative Knowledgebuilding. Linguistics and Education 24,1: 8 - 22.

https://doi.org/10.1016/j.linged.2012.11.005

Maton, K. 2014a. A TALL order?: Legitimation Code Theory for Academic Language and Learning. Journal of Academic Language \& Learning 8,3: $34-38$.

Maton, K. 2014b. Knowledge and Knowers: Towards a Realist Sociology of Education. London: Routledge.

https://doi.org/10.4324/9780203885734

Mazur, E. 2009. Farewell, lecture? Science 323: 50 - 51.

https://doi.org/10.1126/science. 1168927

Macnaught, L., K. Maton, J.R. Martin \& E. Matruglio 2013. Jointly Constructing Semantic Waves: Implications for Teacher Training. Linguistics and Education 24,1: 50 - 63.

https://doi.org/10.1016/j.linged.2012.11.008

Miles, M. B. \& A.M. Huberman, 1994. Qualitative Data Analysis: An Expanded Sourcebook. $2^{\text {nd }}$ Edition. Thousand Oaks, CA, US: Sage Publications. 
Milsom, C. \& M. Yorke 2015. Defining the Second Year. In Milsom, C., M. Stewart, M. Yorke \& E. Zaitseva (eds.): Stepping Up to the Second Year at University: Academic, Psychological and Social Dimensions. London: Routledge. https://doi.org/10.4324/9781315735771

Moje, E. 2007. Developing Socially Just Subject-matter Instruction: A Review of the Literature on Disciplinary Literacy Teaching. Review of Research in Education 31:1 - 44. https://doi.org/10.3102/0091732X07300046001

Morrow, W. 1993. Epistemological Access in the University. AD Issues 1,1: 3 $-4$.

Potgieter, M. \& B. Davidowitz 2011. Preparedness for Tertiary Chemistry: Multiple Applications of the Chemistry Competence Test for Diagnostic and Prediction Purposes. Chemistry Education Research Practice 12:193 - 20. https://doi.org/10.1039/C1RP90024B

Rollnick, M. 2010. Identifying Potential for Equitable Access to Tertiary Level Science: Digging for Gold. Dordrecht: Springer.

https://doi.org/10.1007/978-90-481-3224-9

Rosengrant, D., A. van Heuvelen \& E. Etkina 2009. Do Students Use and Understand Free-body Diagrams? Physical Review Special Topics: Physics Education Research 5: 010108.

https://doi.org/10.1103/PhysRevSTPER.5.010108

Scott, I., N. Yeld \& J. Hendry 2007. A Case for Improving Teaching and Learning in South African Higher Education. Higher Education Monitor 6:1 - 86.

Short, S. \& J. Jürgens 2011. Introducing Concept Mapping as a Teaching and Learning Technique for Life Science ECP Students. In Bozalek, V., J. Garraway \& S. McKenna (eds.): Case Studies of Epistemological Access in Foundation/ Extended Curriculum Programme Studies in South Africa. Cape Town: CPUT.

Singh, C. \& G. Zhu 2011. Improving Students' Understanding of Quantum Mechanics by Using Peer Instruction Tools. Physics Education Research Conference proceedings, Omaha, Nebraska, August 2011: 77 - 80. https://doi.org/10.1063/1.3679998

Smith, L., Case, J. \& C. Van Walbeek 2014. Assessing the Effectiveness of Academic Development Programmes: A Statistical Analysis of Graduation Rates across Three Programmes. South African Journal for Higher Education 28,2: 624 - 638.

Starfield, S. \& F. Hart 1992. Developing a Study Skills Course. South African 
Journal of Higher Education 6,3: 85 - 88.

Tinto, V. 1997. Classrooms as Communities: Exploring the Educational Character of Student Persistence. The Journal of Higher Education 68: $599-623$.

https://doi.org/10.1080/00221546.1997.11779003

Van Heuvelen, A. 1991. Learning to Think like a Physicist: A Review of Research Based Instructional Strategies. American Journal of Physics 59,10: 891 - 897. https://doi.org/10.1119/1.16667

Wieman, C. E. \& K.K. Perkins 2005. Transforming Education. Physics Today 58,11: 36. https://doi.org/10.1063/1.2155756

Winberg, C., V. Bozalek, H. Conana, J. Wright, K.E. Wolff, N. Pallitt \& H. Adendorff 2018. Critical Interdisciplinary Dialogues: Towards a Pedagogy of Well-being in Stem Disciplines and Fields. South African Journal of Higher Education 32,6: 270 - 287.

https://doi.org/10.20853/32-6-2975

Yorke, M. 2015. Why Study the Second Year? In Milsom, C., M. Stewart, M. Yorke \& E. Zaitseva (eds.): Stepping Up to the Second Year at University: Academic, Psychological and Social Dimensions. London: Routledge.

Young, M. \& J. Muller 2013. On the Powers of Powerful Knowledge. Review of Education 1,3: 229 - 250. https://doi.org/10.1002/rev3.3017

Honjiswa Conana Teaching and Learning Specialist, Faculty of Natural Sciences University of the Western Cape cconana@uwc.ac.za

Delia Marshall Department of Physics and Astronomy University of the Western Cape dmarshall@uwc.ac.za

Deon Solomons Department Mathematics and Applied Mathematics University of the Western Cape desolomons@uwc.ac.za 